\title{
Uterus Patolojileri Değerlendirmede Eş Zamanlı Yapılan Histerosalpingografi ve Histeroskopi Sonuçları Benzer mi?
}

\section{Are the Results of Concurrent Hysterosalpingography and Hysteroscopy Similar for Detecting Uterine Pathologies?}

Funda Göde ${ }^{1-3}$,

Ali Sami Gürbüz²,

Gülin Okay ${ }^{3}$

Ahmet Zeki Işık ${ }^{3}$

${ }^{1}$ Bahçeşehir Üniversitesi Tıp Fakültesi, Kadın Hastalıkları ve Doğum Anabilim Dalı,

Istanbul, Türkiye

${ }^{2}$ Novafertil Tüp Bebek Merkezi, Konya Türkiye

3izmir Medikalpark Hastanesi Tüp Bebek

Ünitesi, Izmir, Türkiye

Gelis Tarihi/Received: 04 Mart 2019

Kabul Tarihi/Accepted: 14 Şubat 2019

Yazışma Adresi: Ali Sami Gürbüz,

Novafertil Tüpbebek Merkezi , Konya,

Türkiye

e-posta: alisamigurbuz@hotmail.com

ORCID

Ali Sami Gürbüz

https://orcid.org/0000-0001-7747-3074

\section{GíRiş}

Uterin kavite anormallikleri infertilite şikayeti ile başvuran hastaların yaklaşık \%10-15'inde saptanmaktadır (1). Bu nedenle uterin kavitenin değerlendirilmesi infertilite şikayetiyle gelen bir çiftte

\section{Abstract}

\begin{abstract}
Öz
Amaç: Histerosalpingografi (HSG) genel olarak tubal patensiyi değerlendirmek için kullanılan bir yöntem olsa da uterin patolojileri tespit etmede de yardımcı bir tekniktir. Histerosalpingografinin uterin kavite hastalıklarını değerlendirmedeki duyarlılığını ve histeroskopi ile eş zamanlı karşılaştırmasını değerlendiren çalışma sayısı çok kısıtlıdır. Bu nedenle bu çalışmadaki amacımız histeroskopi ile eş zamanlı yapılan HSG'nin uterin patolojileri değerlendirmedeki duyarlılığını değerlendirmektir.

Hastalar ve Yöntem: Kasım 2017-Eylül 2018 tarihleri arasında Izmir Medicalpark Hastanesi tüp bebek ünitesine başvuran infertil hastaların dosyaları retrospektif olarak tarandı. Aynı gün içerisinde HSG ve histeroskopi uygulanan hastaların verileri incelendi. Hastaların klinik özellikleri (yaş, infertilite süresi, infertilite nedeni, infertilite tipi) değerlendirildi. Hsg ve histeroskopi sonuçları uterus patolojileri açısından karşılaştırıldı.

Bulgular: Calışmaya toplam 114 hasta dahil edildi. HSG ve histeroskopinin genel korelasyonuna baktığımızda 71 (\%62.3) hastada benzer sonuç, 43(\%37.7) hastada ise farklı sonuç elde edildiği görülmüştür. HSG'si normal olarak değerlendirilen 32 hastada ek bir uterin patoloji olduğu gözlendi. Negatif prediktif değer \%44.4 (32/72) olarak saptandı. Histeroskopide polibi saptanan 36 hastanın 12 tanesinde HSG de polip öntanısı mevcuttu. HSG'nin polipler için sensitivitesi 12/36; $\% 37.5$ olarak saptandı. Sonuç: Eş zamanlı uygulanan HSG'nin uterin kaviteyi değerlendirmedeki duyarlılığı düşüktür. Fakat hem tubal patolojilerin hem de uterin patolojilerin aynı zamanda değerlendirilmesini ve es zamanlı tedavisini sağlaması açısından günlük klinik pratikte faydalı olabilir
\end{abstract}

Anahtar Kelimeler: Histeroskopi, histerosalpingografi, intrauterin patoloji

Aim: Hysterosalpingography is usually preferred for evaluation of tubal patency however it is also a helpful technique for detection of uterine pathologies. There is very limited data about the sensitivity of hysterosalpingography for evaluation of uterine cavity diseases. Therefore the aim of our study is to evaluate the sensitivity of hsyterosalpingography for uterine pathologies.

Patients and Methods: The records of infertile patients who applied to Izmir Medicalpark hospital between November 2017 and September 2018 were retrospectively evaluated. Data of patients who had hysterosalpingography and hysteroscopy on the same day were investigated. The clinical characteristics (age, duration of infertility, cause of infertility, type of infertility) of these patients were evaluated. The results of hysterosalpingography and hysteroscopy were compared for uterine pathologies.

Results: A total of 114 patients were included in the study. When the correlation between HSG and hysteroscopy was evaluated, there were similar results in $71(62.3 \%)$ and different results in $43(37.7 \%)$ patients. Extra uterine pathology was detected in 32 patients whose HSG was evaluated as normal. Negative predictive value of HSG was $44 \%$ (32/72) for uterine pathologies. Endometrial polyp was detected in 36 patients during hysteroscopy however the number of patients with initial diagnosis of endometrial polyp was 12 . The sensitivity of hysteroscopy for endometrial polyps was $37.5 \%(12 / 36)$.

Conclusion: The sensitivity of HSG which was applied concurrently with hysteroscopy is low for uterine pathologies. However it might be beneficial in daily clinical practice for evaluating and treating tubal and uterine pathologies at the same time.

Keywords: Hysteroscopy, hysterosalphingography, intrauterin patholohy
Atıf yapmak için: Göde F, Gürbüz AS, Okay G, Işık AZ. Uterus Patolojileri Değerlendirmede Eş Zamanlı Yapılan Histerosalpingografi ve Histeroskopi Sonuçları Benzer mi? Selcuk Med J 2019;35(4): 255-258 temel basamaklardan birisidir. Histerosalpingografi (HSG) tubaları değerlendirmede ilk olarak tercih edilen test olmakla birlikte konjenital ve edinilmiş uterin patolojileri değerlendirmede de transvajinal ultrasonografi'den sonra çok yaygın olarak 
kullanılmaktadır. HSGilesubmukozmyomlar, dismorfik uteruslar, endometrial polipler, uterin sineşiler ve konjenital müllerian anomaliler tespit edilebilmektedir (2). HSG'de bazı intrauterin lezyonlarda tanıdan ziyade bir ön tanı ya da patoloji şüphesi konulmaktadır. Sonraki aşamada ise genelde histeroskopi ile tanıyı konfirme etmek ya da edilebilyorsa tedavi etmek gerekir (3). Histeroskopi endometrial kaviteyi değerlendirmede altın standart olarak kabul edilen bir yöntemdir (4). Aynı zamanda görülen patolojileri tedavi şansı sağlaması da diğer bir avantajıdır. Histeroskopinin dezavantajı is myometrium, tubalar ve adneksler ile ilgili bilgi vermemesidir. O nedenle tek başına kadın infertilitesini değerlendirmede yeterli olamamakta, hsg ya da laparaskopi ile kombinasyonu gerekmektedir.

Uterin patolojileri değerlendirmede HSG'nin duyarlılığını değerlendiren çok fazla çalışma yoktur. Soares et al. nın çalışmasında hastaların transvaginal ultrasonografi, sonohisterografi, histerosalpingografi ve histeroskopi sonuçları değerlendirilmiştir. 65 hastanın dahil edildiği çalışmada polipoid lezyonlar, uterin malformasyonlar, intrauterin adezyonlar ve endometrial hiperplazi açısından sonuçlar karşılaştırılmıştır. HSG'nin polipler için sensitivitesi $\% 50$, endometrial hiperplazi için $\% 0$, uterin malformasyonlar için \%44.4, intrauterin adezyonlar için ise \%75 olarak saptanmıştır (3). HSG ile histeroskopi korelasyonuna bakıldığında az sayıdaki eski çalışma sonuçlarına göre ortalama \%30 oranında görüş ayrılığı olabildiği bildirilmektedir $(2,4,5)$

Şimdiye kadar yapılan çalışmalarda uterin patolojileri değerlendirmede HSG'nin duyarlılığını araştıran çalışmalar mevcut olsa da bu çalışmaların çoğunluğunda HSG çekildikten belirli bir süre sonra histeroskopi uygulanmıştır. Fakat bu zaman aralığında polip ve sineşi gibi patolojiler sonradan gelişebileceği için karşılaştırma tam sağlıklı olamamaktadır. Bu nedenle bu çalışmada amacımız aynı gün içerisinde uygulanan eş zamanlı HSG ve Histeroskopi sonuçlarını uterus patolojileri açısından karşılaştırmaktır.

\section{HASTALAR VE YÖNTEM}

Çalışmada Kasım 2017-Eylül 2018 tarihleri arasında İzmir Medicalpark Hastanesi tüp bebek ünitesine infertilite şikayetiyle başvuran hastalardan aynı gün içerisinde histerosalpingografi ve histeroskopi uygulanan hastaların dosyaları retrospektif olarak incelendi. Hastaların klinik özellikleri (yaş, infertilite süresi, infertilite nedeni, infertilite tipi, doğum sayısı) incelendi. Hsg ve histeroskopi sonuçları uterin patolojiler açısından değerlendirildi. İki teknikte saptanan sonuçlar karşılaştırıldı. HSG'nin uterin patolojiler açısından sensitivite, spesifisite, pozitif prediktif değer ve negatif prediktif değerleri hesaplandı. İstatistiksel analizde SPSS 20 kullanıldı.

\section{BULGULAR}

Hastaların klinik özellikleri Tablo 1'de özetlenmiştir. Çalışmaya toplam 114 hasta dahil edildi. Ortalama yaş $34.61 \pm 5.61$, infertilite süresi $3.57 \pm 2.66$ yıl, doğum sayısı $0.27 \pm 0.55 \mathrm{idi}$. İnfertilite nedenlerine bakıldığında büyük kısmını düşük over rezervi olan hastalar oluşturmaktaydı (45 hasta). Daha sonra sırasıyla tubal faktör, açıklanamayan infertilite, erkek faktör, polikistik over sendromu, endometriozis, asherman sendromu mevcuttu. 4 olguda ise tekrarlayan gebelik kaybı vardı. Olguların 68 tanesi (\%59.6) primer infertilite 46 tanesi (\%40.4) ise sekonder infertilite nedeniyle başvurmuştu. Hastaların HSG ve Histeroskopi sonuçları Tablo2'de özetlenmiştir. HSG sonuçlarına baktığımızda 72 hastada (\%63.2) normal uterin kavite, 12 hastada (\%10.5) polip, 12 hastada (\%10.5) dismorfik uterus, 6 hastada(\%5.3) uterin sineşi, 6 hastada (\%5.3) istmosel, 4 hastada (\%3.5) uterin septum, 2 hastada arkuat uterus (\%1.8) saptandı. Hastaların HSG sonrası hemen çekilen histeroskopilerinde ise 40 hastada (\%35.1) normal uterin kavite, 36 hastada (\%31.6) polip, 11 hastada (\%9.6) dismorfik uterus, 3 hastada(\%2.6) uterin sineşi, 12 hastada $(\% 10.5)$ istmosel, 6 hastada (\%5.3) uterin septum, 4 hastada arkuat uterus (\%3.5), 1 hastada(\%0.9) submukoz myom, 1

Tablo 1. Hastaların klinik özellikleri

\begin{tabular}{lll}
\hline & Ortalama & \\
\hline Yaş (y) & $34.61 \pm 5.61$ & \\
İnfertilite süresi $(y)$ & $3.57 \pm 2.66$ & \\
Doğum sayısı & $0.27 \pm 0.55$ & \\
İnfertilite nedeni & Sayı & $\%$ \\
Düşük over rezervi & 45 & 39.5 \\
Tubal Faktör & 13 & 11.4 \\
Açıklanamayan & 15 & 13.2 \\
Polikistik Over sendromu & 15 & 13.2 \\
Erkek Faktör & 15 & 13.2 \\
Endometriozis & 6 & 5.3 \\
Asherman sendromu & 1 & 0.9 \\
Tekrarlayan gebelik kaybı & 4 & 3.5 \\
Toplam & 114 & 100 \\
İnfertilite tipi & Sayı & $\%$ \\
Primer & 68 & 59.6 \\
Sekonder & 46 & 40.4 \\
Toplam & 114 & 100 \\
\hline
\end{tabular}


Tablo 2. Hastaların HSG ve Histeroskopi bulguları

\begin{tabular}{lll}
\hline Uterus & HSG & Histeroskopi \\
\hline Normal & $72(\% 63.2)$ & $40(\% 35.1)$ \\
Endometrial Polip & $12(\% 10.5)$ & $36(\% 31.6)$ \\
Dismorfik uterus & $12(\% 10.5)$ & $11(\% 9.6)$ \\
Uterin sineşi & $6(\% 5.3)$ & $3(\% 2.6)$ \\
İstmosel & $6(\% 5.3)$ & $12(\% 10.5)$ \\
Septum & $4(\% 3.5)$ & $6(\% 5.3)$ \\
Arkuat & $2(\% 1.8)$ & $4(\% 3.5)$ \\
Submukoz myom & $0(\% 0)$ & $1(\% 0.9)$ \\
Adenomyosis & $0(\% 0)$ & $1(\% 0.9)$ \\
Toplam & $114(\% 100)$ & $114(\% 100)$ \\
\hline
\end{tabular}

hastada (\%0.9) ise adenomyotik odaklar saptandı. HSG'sinde kavitesi normal olarak değerlendirilen 36 hastada ek bir patoloji olduğu gözlendi. Genel sonuçlara bakıldığında HSG'nin sensitivitesi \%51.35 (38/74); spesifisitesi \%90 (36/40); Pozitif prediktif değeri: \%90.4(38/42) Negatif prediktif değeri de \%50 (36/72) olarak saptandı (Tablo 3). Endometrial poliplere bakıldığında histeroskopide polibi saptanan 36 hastanın 12 tanesinde HSG de polip öntanısı mevcuttu. HSG'nin polipler için sensitivitesi 12/36; \%37.5 olarak saptandı. Histeroskopide istmosel saptanan 12 hastanın 6 tanesinde HSG'de istmosel öntanısı mevcuttu. HSG'nin istmosel için sensitivitesi 6/12; \%50 olarak saptandı. Sineşilere bakıldığında ise kavitede HSG'de 6 hastada sineşi öntanısı mevcuttu ve bu hastaların tamamı histeroskopide saptandı. Dismorfik uterus ön tanısıyla histeroskopi yapılan hastaların hastaların tamamında benzer bulgu saptandı. HSG ve histeroskopinin genel korelasyonuna baktığımızda 71 (\%62.3) hastada benzer sonuç $43(\% 37.7)$ hastada ise farklı sonuç elde edildiği görülmüştür. Takip ve tedavi sonucunda bu hastaların 38 (\%33.3)' inde klinik gebelik elde elde edilmiştir. Diğer hastaların takip ve tedavisi ise devam etmektedir.

\section{TARTIŞMA}

Histerosalpingografi infertil çiftlerin değerlendirmesinde en yaygın kullanılan yöntemlerden birisidir. Özellikle tubalar ile ilgili bilgi edinmede faydalı

Tablo 3. HSG ve Histeroskopinin genel bulguları

\begin{tabular}{|c|c|c|c|}
\hline \multicolumn{4}{|c|}{ Histeroskopi } \\
\hline HSG & Anormal & Normal & Toplam \\
\hline Anormal & 38 & 4 & 42 \\
\hline Normal & 36 & 36 & 72 \\
\hline Toplam & 74 & 40 & 114 \\
\hline
\end{tabular}

bir yöntemdir. Uterin kavitenin değerlendirilmesinde ise daha ikincil bir yöntem olarak tercih edilmesine rağmen kavite düzensizlikleri, polipler ve myomlar gibi pek çok patolojinin ön tanısını sağlamaktadır. Bizim çalışma sonuçlarımız da HSG ile pek çok uterin kavite anormalliğinin ön tanısının konulabildiğini desteklemektedir. Histerosalpingografi uterin kavite problemlerini değerlendirmedeki güvenilirliği değerlendirildiğinde histeroskopi klavuz yöntem olarak kullanılmaktadır. Çalışma sonuçlarına genel olarak bakıldığında HSG'nin kavite problemlerini tespit etmedeki sensitivitesinin yüksek, spesifisitesinin ise düşük olduğu gözlenmektedir (3-9). Yani HSG yanlış pozitifliği ve yanlış negatifliği yüksek bir testtir. Roma Dalfo et al. çalışmasında histeroskopi ile karşılaştırıldığında HSG'nin intrauterin anormallikleri tespit etmedeki değerine bakıldığında; \%81 sensitivite, $\% 80$ spesifisite, \%9 yanlış negatiflik ve \%22 yanlış pozitiflik saptanmıştır (5). Yine başka bir çalışmada $\% 18$ yanlış pozitiflik ve \%19 yanlış negatiflik oranıyla HSG'nin \%79 sensitif, \%82 spesifisifik bir test olduğu belirtilmiştir (8).

Sonuçlarımıza göre eş zamanlı yapılan HSG ve histeroskopide kavite şeklini (dismorfik uterus) ve sineşileri değerlendirmede hsg ve histeroskopi sonuçlarının büyük oranda benzer olduğu gözlendi. İntrauterin polip ve istmoseli değerlendirmede histeroskopide saptanan patolojilerin büyük bir kısmının HSG'de tespit edilemediği saptandı. Yani kavite içi patolojileri değerlendirmede eş zamanlı yapılan HSG'nin duyarlılığı düşüktü. HSG'de dolum defekti olarak görülen patolojik görüntüler polip, hiperplazi, submukoz myom ya da intrauterin adezyonlar olabilir. Dolum defektinin tipine bağlı olarak bir ön tanı koyulabilse de bizim sonuçlarımızada da olduğu gibi yanılma payı yüksek olabilmektedir. Bu nedenle HSG sadece ön tanıda kullanılmakta kesin tanı ve gerekirse tedavide histeroskopi uygulanmalıdır. HSG'deki hatalı sonuçlar pek çok faktöre bağlı olabilir ve çekimin menstrual siklusun hangi fazında yapıldığı da bu faktörlerden birisidir. Kliniğimizde HSG ve histeroskopi işlemleri menstruasyonun hemen sonrasında ya da oral kontraseptif kullanılırken yapıldığı için sonuçlarımızın menstrüel siklustan etkilenmediğini kabul edebiliriz. Hava kabarcığı oluşması, mukus veya menstrual debris gibi nedenlerle yanlış pozitif sonuçlar görülebilir. Kontrast maddenin çok hızlı verilmesine bağlı olarak da polip gibi küçük lezyonlar ya da adezyonlar atlanabilir (3). Bizim çalışma sonuçlarımıza göre de özellikle polipler konusunda HSG'nin sensitivitesinin 
düşük olması poliplerin kontrast maddenin gölgesinde kalması ile açıklanabilir. Ayrıca HSG ile inflammatuar ya da enfektif lezyonlar da tespit edilememektedir. Bu nedenle bazı otörlerce infertil hastalarda kavitenin değerlendirlmesinde histeroskopi rutin olarak önerilmiştir (9). Son yıllarda yeni gündeme gelen bir diğer konu da istmosel vakalarıdır. İstmosel tanısı transvaginal ultrasonografi ile koyulabilse de, literatürde HSG'nin istmoseli tespit etmedeki rolü ile ilgili veri mevcut değildir $(10,11)$. Sonuçlarımıza göre histeroskopide 12 adet istmoseli olan hastanın 6 tanesi HSG'de tespit edilebilmiştir. Bu sonuçlara göre HSG'nin istmosel tanısında da yanlış negatiflik oranının yüksek olduğunu söyleyebiliriz. Bu konuyla ilgili daha fazla veriye intiyaç vardır.

Bizim çalışmamızın literatüre ek katkısı nedir? Literatüre bakıldığında HSG ve histeroskopinin duyarlıı̆̆ ile ilgili çalışmalar mevcut olmasına rağmen eş zamanlı HSG ve histeroskopiyi karşılaştıran çalışma yok denecek kadar azdır $(12,13)$. Cevrioglu et al. çalışmasına 72 hasta dahil edilmiş, karşılaştırma yapılmamış sadece sonuçlar değerlendirilmiştir. 47 hastada normal 25 hastada patolojik bulgular saptanmış. Ofis histeroskopi ile düzeltilen endometrial patolojilerin oranı \%25 olarak saptanmıştır. Çalışmada vurgulanmak istenen eş zamanlı HSG ve histeroskopi kombinasyonuyla hastalarda tubal patolojileri tespit edebiliyorken endometrial patolojileri de görerek tedavi etme şansı olmasıdır. Bizim hasta grubumuzda da 10 hastada HSG'de hidrosalpinks saptanmıştır. Bu vakalarda da koterizasyon yöntemi ile histeroskopik kornual blokaj uygulanabilmesi diğer bir avantajdır. Biz de kliniğimizde eş zamanlı olarak histeroskopik kornual blokaj uygulamaktayız. Eş zamanlı yapılan HSG ve histeroskopi ile böylece morbiditesi daha yüksek bir operasyon olan laparoskopiye gerek kalmadan infertilite hastalarında hidrosalpinksin tespit ve tedavisi de mümkün olmaktadır. Literatürde bunula ilgili çok az sayıda vaka serileri içeren sadece iki yayın mevcuttur $(14,15)$. Konuyla ilgili geniş çaplı çalışmalara intiyaç vardır.

Sonuç olarak HSG'nin uterin kaviteyi değerlendirmedeki duyarlılığı düşüktür. Fakat hem tubal patolojilerin hem de uterin patolojilerin aynı zamanda değerlendirilmesini ve eş zamanlı tedavisini sağlaması açısından günlük klinik pratikte eş zamanlı HSG ve histeroskopi uygulaması faydalı olabilir. Özellikle hidrosalpinks vakalarında da yeni bir yaklaşım olarak yaygın kullanımı gündeme gelebilir. Konuyla ilgili maliyet ve hasta memnuniyeti verileri açısından ek çalışmalara ihtiyaç vardır.
Çıkar Çatışması: Çalışmada herhangi bir çıkar çatışması yoktur.

Finansal Çıkar Çatışması: Çalışmada herhangi bir finansal çıkar çatışması yoktur.

Yazışma Adresi: Ali Sami Gürbüz, Novafertil Tüpbebek Merkezi Yeni Meram Yolu No: 75, Meram, Konya, Türkiye

GSM: 05335530442 e-mail: alisamigurbuz@hotmail.com

\section{KAYNAKLAR}

1. Bingol B, Gunenc Z, Gedikbasi A, et al. Comparison of diagnostic accuracy of saline infusion sonography, transvaginal sonography and hysteroscopy. Journal of Obstetrics and Gynecology 2011;31(1):54-8.

2. Brown SE, Coddington CC, Schnorr J, et al. Evaluation of outpatient hysteroscopy, saline infusion hysterosonography and hysterosalpingography in infertile women: A prospective randomized study. Fertil Steril 2000;74:1029-34.

3. Pundir J, Toukhy TE. Uterine cavity assessment prior to IVF. Women's Health 2010;6(6):841-8.

4. Siegler AM. Hysterography and hysteroscopy in the infertile patient. J Rep Med 1977;18-143-8.

5. Valle RF. Hysteroscopy in the evaluation of female infertility. Am J Obstet Gynecol 1980;137:425-31.

6. Soares SR, Barbosa dos Reis MM, Camargos AF. Diagnostic accuracy of sonohysterography, transvaginal sonography, and hysterosalpingography in patients with uterine cavity diseases. Fertil Steril 2000;73:406-11.

7. Roma Dalfo A, Ubeda B, Ubeda A, et. al. Diagnostic value of hysterosalpingography in the detection of intrauterine abnormalities: A comparison with hysteroscopy. AJR Am J Roentgenol 2004;183(5):1405-9.

8. Ganglione R, Valentini AL, Pistilli E, et al. A comparison of hysteroscopy and hysterosalpingography. Int J Gynecol Obstet 1996;52(2):151-5.

9. Golan A, Eilat E, Ron-El R. Hysteroscopy is superior to hysterosalpingography in infertility investiagtion. Acta Obstet Gynecol Scand 1996;75(7):654-6.

10. Valenzona M, Lijoi D, Mistrangelo $E$, et al. Vaginal ultrasonographic and hysterosonographic evaluation of the low transvers incision after cesarean section; correlation with gynecological symptoms. Gynecol Obstet Invest 2006;61:216-22.

11. Osser Ov, Jakubkiene L, Valentin L. High prevalance of defects in Cesarean section scars at transvaginal ultrasound examination. Ultrasound Obstet Gynecol 2009;34:90-7.

12. Chauhan MB, Lakra P, Nanda S, et al. Hysterosalpingography vs hysteroscopy: Role in assessment of uterine factor during infertility workup. J South Asian Feder Obst Gynae 2013; 5(3):116-9.

13. Cevrioglu AS, Darol YV, Bostanci MS, et al. Combined use of office hysteroscopy and hysterosalpingography: A novel combination in infertility work-up. J Min Invasive Gynecol 2017;24;S1-201.

14. Bao HC, Wang MM, Wang XR, et al. Clinical application of operative hysteroscopy in treatment of complex hydrosalpinx prior to IVF. Iran J Reprod Med 2015;13(5):311-6.

15. Darwish AM, Saman AE. Is there a role for hysteroscopic tubal occlusion of functionless hydrosalpinges prior to IVF/ ICSI in modern practice. Acta Obstetrica et Gynecologica 2007;86:1484-9. 